\title{
BRACHYDACTYLY WITH ABSENCE OF MIDDLE PHALANGES AND HYPOPLASTIC NAILS*
}

\author{
A New Hereditary Syndrome \\ Alejandro Cuevas-Sosa $\nmid$ and Francisco García-Segur, Mexico City, Mexico \\ From the Servicio de Genética Humana, Hospital General, México City
}

Hereditary anomalies of hands and feet are diverse and have been well described. Brachydactyly is a feature of several disorders; classification has been based on whether the metacarpal bones, metatarsal bones or phalanges are affected (Bell 1951, McKusick 1968, Temtamy and McKusick 1969). Generally, nail dystrophy does not accompany brachydactyly, but a recent report (Bass 1968) described a family whose brachydactyly was also accompanied by nail dysplasia. This paper deals with a seven-generation family which has throughout presented variable degrees of brachydactyly, characterised by hypoplastic nails from the index to the little fingers, normal toe nails, absent middle phalanges in the fingers and in the lateral four toes, variable degrees of hypoplasia of the distal phalanges in the fingers, but with normal thumbs and normal big toes. The disorder seems to represent an undescribed variety of brachymesodactyly and nail dystrophy.

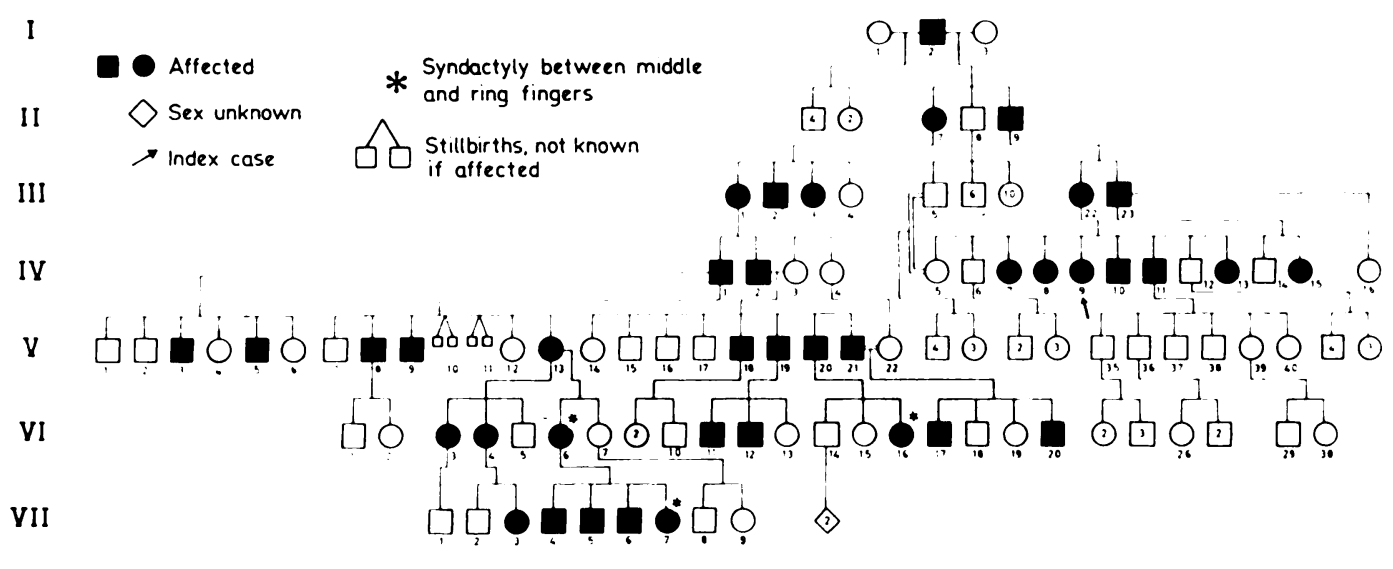

Fig. 1

The seven-generation family with brachydactyly.

FAMILY STUDY

The pedigree is shown in Figure 1. The disorder began in about 1800 with the birth of a Mexican boy of Spanish descent who is considered the first affected family member and whose degree of anomalies is unknown. An unmarried eighty-one-year-old woman (IV-9) who only wanted to find out the nature of her affected hands was referred to our service. She was in good health when first seen. Attention was mainly focused on her hands. She presented brachydactyly of the second, third, fourth and fifth fingers with severely hypoplastic nails and normal thumbs. Some fingers had lost their rudimentary nails. The patient believed that the disorder was located only in her hands and that she had normal feet. At first glance the

* Presented in part at the Eighth International Congress of the International Academy of Pathology, Mexico City, May 14, 1970.

† This paper is dedicated with gratitude and indebtedness to Dr Salvador Aceves Parra.

VOL. 53 B, NO. 1, FEBRUARY 1971 
feet looked normal, but on detailed inspection they showed normal nails but only one flexion fold on each toe. Radiographs of the hands and feet showed normal thumbs and big toes but absence of middle phalanges in the index to little fingers (Fig. 2) and in the four lateral toes. The proximal and distal phalanges of the feet appeared normal (Figs. 3 and 4). In most of the patients studied the proximal phalanges of the hands looked normal and the distal ones in the index to little fingers showed variable degrees of shortening. In Case VI-4 the

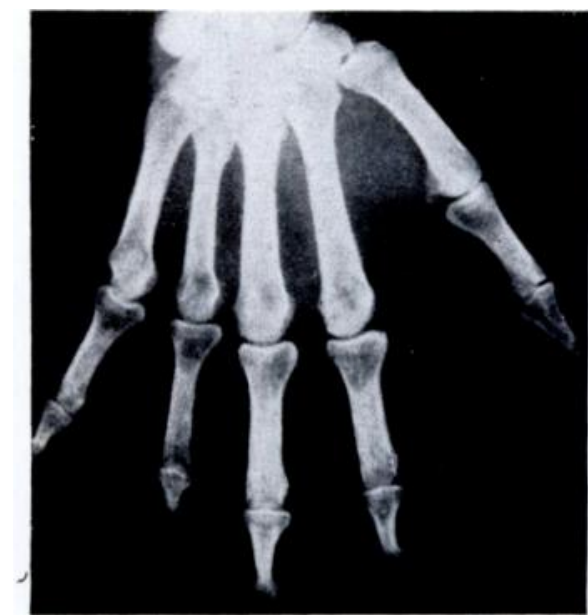

FIG. 2

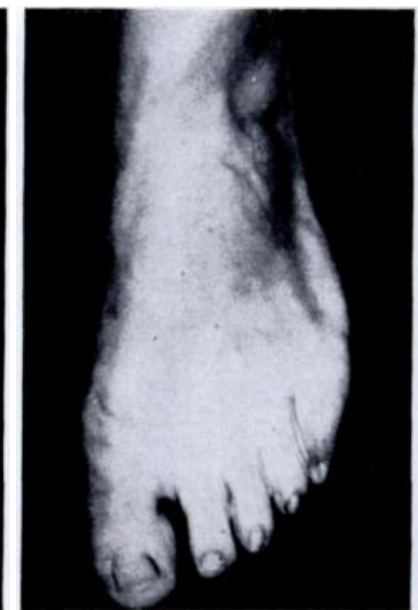

Fig. 3

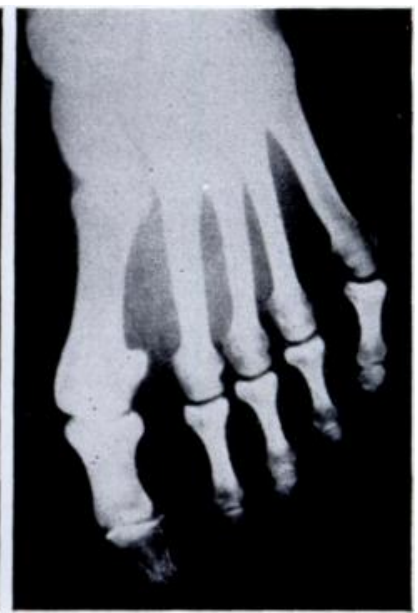

Fig. 4

Figure 2-Case IV-9. Radiographs of the right hand of the proposita. The thumb is normal as are the proximal phalanges, in contrast to the absence of the middle phalanges and hypoplasia of the distal phalanges. Figure 3The clinical appearance of left foot and (Fig. 4) the radiograph. The big toe is normal as are all the other toe nails but there is absence of the middle phalanges, but the distal and proximal phalanges are normal.

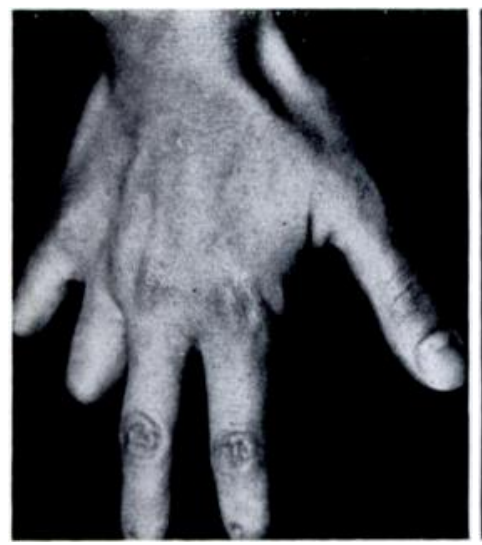

Fig. 5

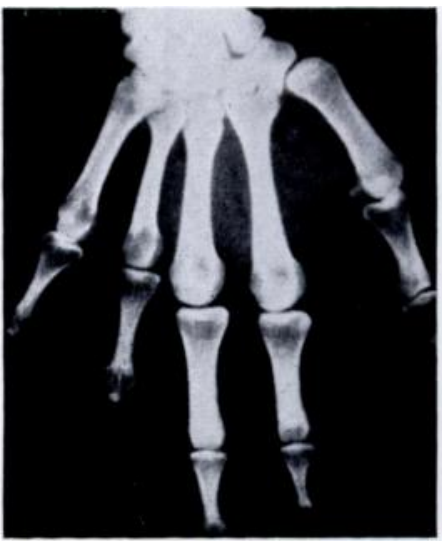

Fig. 6

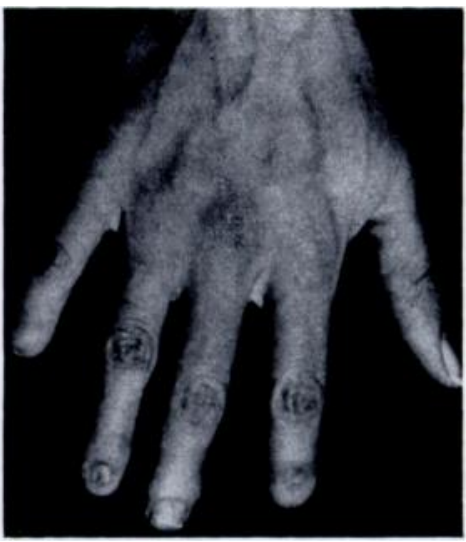

Fig. 7

Figure 5-Case VI-4. The right hand in which the thumb is normal, but all the other fingers are much affected. In the radiograph (Fig. 6) the normal thumb and the rudimentary distal phalanges of the ring and little fingers are shown as is the narrowing of the proximal phalanges of the same fingers. Figure 7-The right hand of patient VI-3. The thumb is normal but there are half-developed nails of the middle and ring fingers with absence of nails on the index and little fingers.

proximal phalanges of the ring and little fingers looked thinner than normal. This anomaly was found only in this patient (Figs. 5 and 6).

Of this family it was possible to study the following affected members: IV-9, V-13, V-20, VI-3, VI-4, VI-6, VI-16, VII-3, VII-4, VII-5, VII-6 and VII-7. This family study confirmed that the anomaly in the feet was the same in all those affected. In the affected hands, however, there were variations in the degree of the anomaly. The middle phalanges were 
always absent, but there was variation in the degree of hypoplasia of the distal phalanges and nails. In the affected fingers the nails developed at most to half normal size (Fig. 7), the larger nails being associated with the more developed distal phalanges. The ring and little fingers were usually more severely affected than the index and middle, showing in some patients a very small distal phalanx and absence of the nail. At the very least, a rudimentary distal phalanx was always found (Fig. 6). When a finger showed a rudimentary nail it would usually be dislodged by the slightest injury. In three patients, VI-6, VI-16 and VII-7, syndactyly between the middle and ring fingers of the left hand-which had been surgically corrected-

TABLE I

Analysis of Offspring of Affected Persons

\begin{tabular}{|c|c|c|c|c|c|c|}
\hline & & & Affected & $\begin{array}{c}\text { Not } \\
\text { affected }\end{array}$ & Total & $\begin{array}{l}\text { Statistical } \\
\text { analysis }\end{array}$ \\
\hline \multicolumn{7}{|c|}{$\begin{array}{l}\text { Offspring of affected } \\
\text { males }\end{array}$} \\
\hline Male . & . & . & 14 & 20 & 34 & $x^{2}=1.449$ \\
\hline \multirow[t]{2}{*}{ Female. } & . & . & 5 & 15 & 20 & d.f. $=1$ \\
\hline & & & 19 & 35 & 54 & $P>0.20$ \\
\hline \multicolumn{7}{|c|}{$\begin{array}{l}\text { Offspring of affected } \\
\text { females }\end{array}$} \\
\hline Male & . & . & 8 & 5 & 13 & $x^{2}=0.941$ \\
\hline \multirow[t]{2}{*}{ Female . } & . & . & 11 & 3 & 14 & d.f. $=1$ \\
\hline & & & 19 & 8 & 27 & $P>0.30$ \\
\hline \multicolumn{4}{|c|}{$\begin{array}{l}\text { Offspring of affected } \\
\text { males and females }\end{array}$} & & & \\
\hline Male . & . & . & 22 & 25 & 47 & $x^{2}=0.000507$ \\
\hline \multirow[t]{2}{*}{ Female . } & . & . & 16 & 18 & 34 & d.f. $=1$ \\
\hline & & & 38 & 43 & 81 & $P>0.99$ \\
\hline
\end{tabular}

was observed. No other bones were found to be affected in the patients studied, nor was there any abnormality of stature or other abnormal physical trait: weight, bodily proportions and intelligence were normal. There was no cardiac anomaly detected, nor was any ocular abnormality or defect of hearing found. The skin, hair and sweat physiology were also normal.

The characteristics of the hereditary pattern are: 1) males and females were alike affected or transmitted the anomaly; 2) there was male to male transmission; and 3) there was no "skipping" of generations. The statistical analysis of this family by means of a two- $x$-two table approach is shown in Table I. As expected, the $x^{2}$ tests agree very well with autosomal dominant inheritance.

\section{DISCUSSION}

It is interesting that the pleomorphism in this process follows the pattern characteristic of autosomal dominant inheritance, in which the most severely affected members give rise to less affected children and the converse. At the same time, close relatives show variation of affection and distant relatives have similar anomalies (Bell 1951). Psychologically, this anomaly has had serious results on the life of several of the females of the kindred because in a few cases marriage was avoided as a result of a lack of understanding of the problem.

There are apparently no cases of lack of penetrance: we investigated carefully descendants

VOL. 53 B, NO. 1, FEBRUARY 1971 
of IV-11, with negative results. Expression of the mutant gene differs only in respect of the hand anomalies; the foot anomalies seemed to be constant.

According to McKusick (1968) and Temtamy and McKusick (1969), the following main types of brachydactyly have been described. Type $A 1$ is characterised by middle phalanges that may be rudimentary or fused with the terminal phalanx. The proximal phalanges of the thumbs and big toes are short and so is the height of these subjects. In Type $A 2$ shortening of the middle phalanges is shown, which is confined to the index finger and the second toe, all other digits being more or less normal. In $T_{y}$ pe $A 3$ there is shortening of the middle phalanx limited to the little finger with clinodactyly. In Type $A 4$ the main feature is brachymesophalangy affecting the second and fifth digits. The fourth digit, when affected, shows an abnormally shaped middle phalanx leading to radial deviation of the distal phalanx. The feet also show absence of the middle phalanges of the lateral four toes. In Type $B$ the middle phalanges are short and the terminal phalanges are rudimentary or absent. Fingers and toes are affected. The thumbs and big toes are usually deformed. In the feet there is syndactyly usually between the second and third toes. Type $C$ presents brachydactyly of the middle phalanx of the index and middle fingers, triangulation of the fifth middle phalanx, brachymetapody, hyperphalangy and symphalangism. Type $D$ is characterised by short and broad terminal phalanges of the thumbs and big toes. Type $E$ shows brachydactyly mainly due to shortening of the metacarpals and metatarsals. Wide variability in the number of affected digits occurs from person to person. The patients are moderately short and have round facies.

The syndrome reported by Bass (1968) is characterised by "brachydactyly, hypoplastic fingers and second toe nails, absent middle phalanges in the fingers and lateral four toes, duplicated distal phalanges of the thumbs, and possible hypoplasia of the auricular cartilage". The main differences with the presently reported syndrome is that the thumbs and second toe nail are always normal while in the cases described by Bass they were also affected. Another type of brachydactyly is that associated with affected metacarpal bones, metatarsal bones, strabismus, mental deficiency and cerebellar ataxia (McKusick 1968). The syndrome herein reported cannot be confused with several other hereditary disorders associated with nail dystrophy (Lees, Lawler, Renwick and Thoday 1957; Schröder 1961), such as the nailpatella syndrome (Schröder 1961).

There is also no possibility of confusion with some forms of ectodermal dysplasia, that is, chondroectodermal dysplasia of the Ellis-van Creveld type (Ellis and van Creveld 1940), anhidrotic or hidrotic ectodermal dysplasia (Clouston 1929, Mackay and Davidson 1929, Bowen 1957) in which there are many other anomalies not found in the presently reported syndrome, and also, in the first two, the pattern of hereditary transmission is different. The Ellis-van Creveld syndrome is autosomal recessive and the anhidrotic ectodermal dysplasia is sex-linked recessive. The hidrotic ectodermal dysplasia (McKusick 1968) is inherited as an autosomal dominant and is clinically characterised by normal function of sweat and sebaceous glands, total alopecia, severe dystrophy of the nails, hyperpigmentation of the skin-especially over the joints-and normal teeth. Other findings such as strabismus or mental deficiency are occasionally found. This disorder is quite different from that which we report.

It is worth while to emphasise the difference between the consequences of the mutant gene in hands and feet; in hands the middle phalanx was absent and the distal one was usually considerably affected and closely related to the degree of nail anomaly; in the feet there was found only the absence of the middle phalanx, with a normal distal phalanx and nail. The great variability found in genetic anomalies of hands and feet-which follows a Mendelian pattern-speaks of the many functionally interrelated alleles which govern the embryonic differentiation of hands and feet, with mutations producing specific anomalies, which are sometimes difficult to distinguish individually because they are so similar that each appears to mimic the other. There are, however, several well described instances which can be classified as specific entities and we believe that the syndrome described here represents another. 


\section{SUMMARY}

1. A seven-generation family is described which presented an autosomal dominant hereditary disorder characterised by brachydactyly, hypoplastic nails from the index to the little fingers, normal toe nails, absent middle phalanges in the fingers and lateral four toes, variable degrees of hypoplasia of the distal phalanges in the fingers with normal thumbs and normal big toes. 2. Less frequently syndactyly between middle and ring fingers on the left and narrowing of the proximal phalanges of the ring and little fingers are also found.

3. This disorder seems to represent a new hereditary syndrome.

\section{REFERENCES}

Bass, H. N. (1968): Familial Absence of Middle Phalanges with Nail Dysplasia: a New Syndrome. Pediatrics, 42, 318.

Bel., J. (1951): On Brachydactyly and Symphalangism. In Pearson, K., ed.: Treasury of Human Inheritance, Vol. 5, part 1. London: Cambridge University Press.

Bowen, R. (1957): Hereditary Ectodermal Dysplasia of the Anhidrotic Type. Southern Medical Journal, 50, 1018.

Clouston, H. R. (1929): A Hereditary Ectodermal Dystrophy. Canadian Medical Association Journal, $21,18$.

Ellis, R. W. B., and Creveld, S. van (1940): A Syndrome Characterized by Ectodermal Dysplasia, Polydactyly, Chondro-dysplasia and Congenital Morbus Cordis. Report of Three Cases. Archives of Disease in Childhood, 15, 65.

Lees, D. H., Lawler, S. D., Renwick, J. H., and Thoday, J. M. (1957): Anonychia with Ectrodactyly: Clinical and Linkage Data. Annals of Human Genetics, 22, 69.

McKusick, V. A. (1968): Mendelian Inheritance in Man. Second edition, p. 24. Baltimore: The Johns Hopkins Press.

Mackay, H., and Davidson, A. M. (1929): Congenital Ectodermal Defect. British Journal of Dermatology and Syphilis, 41, 1.

SCHRÖDER, G. (1961): Osteo-Onycho-Dysplasia hereditaria. Zeitschrift für menschliche Vererbungs- und Konstitutionslehre, 36, 42.

Temtamy, S., and McKusick, V. A. (1969): Synopsis of Hand Malformations with Particular Emphasis on Genetic Factors. In Bergsma, D., et al., eds.: The First Conference on The Clinical Delineation of Birth Defects, Part III-Limb Malformations. New York: The National Foundation-March of Dimes. 